\title{
The Clinical and Uropathological Aspects of Neuroendocrine Tumours of the Bladder: A Review
}

\author{
(D) Büşra Yaprak Bayrak \\ Kocaeli University Faculty of Medicine, Department of Pathology, Kocaeli, Turkiye
}

\section{What's known on the subject? and What does the study add?}

Primary neuroendocrine tumors of the bladder are extremely rare tumors. Since metastatic tumors are seen more often, it is necessary to distinguish between primary and secondary tumors. Histopathological and immunohistochemical examination gains importance at this stage. With this review, it is aimed to improve the uropathological perspective and to guide the treatment to be given. At the same time, this review is emphasized that most neuroendocrine-like tumors do not have histological features compatible with neuroendocrine bladder tumors, but phenotypically resemble traditional urothelial carcinoma.

\begin{abstract}
Neuroendocrine tumours of the bladder are less common than other histologic types (e.g., urothelial carcinoma, squamous cell carcinoma, adenocarcinoma), constituting 1\% of malignant bladder cancers. Based on the "2016 World Health Organization Classification of Tumours of the Urinary System and Male Genital Organs", neuroendocrine tumours are classified into four subtypes: small cell neuroendocrine carcinoma (SCNC), large cell neuroendocrine carcinoma (LCNC), well-differentiated neuroendocrine tumour (carcinoid tumour) and paraganglioma. SCNC is more common than other subtypes, and LCNC is exceedingly rare in the bladder. Although neuroendocrine tumours are not as common as neuroendocrine neoplasms of the lungs, the differential diagnosis of these tumours remains crucial and should be considered in uropathology. Neuroendocrine tumours of the bladder can present with distinctive morphology and grades, similar to their pulmonary counterparts. The knowledge of this diagnosis is critical to advance the uropathological field and accelerate drug development with inclusion, rather than exclusion, of patients with SCNC and other variants of neuroendocrine tumours of the bladder. Therefore, in this review, the bladder's clinical and uropathological aspects of neuroendocrine tumours are reviewed. This classification provides a useful platform to discuss the aetiology, pathogenesis, clinical and pathological characteristics and treatment of the neuroendocrine tumours of the urinary bladder. The overall prognosis of urinary bladder neuroendocrine tumours is worse than urothelial carcinoma. Various advances are expected in the clinical characterisation, prognostication and treatment of neuroendocrine tumours of the bladder with the technologies developed in genetic and cellular investigations.
\end{abstract}

Keywords: Bladder cancer, neuroendocrine tumours, small cell carcinoma, large cell neuroendocrine carcinoma

\section{Introduction}

Neuroendocrine tumours of the bladder are less common than the other histologic variants (e.g., urothelial carcinoma, squamous cell carcinoma, adenocarcinoma) in the genitourinary system, constituting 1\% of malign bladder cancers (1). Based on "2016 World Health Organization (WHO) Classification of Tumours of the Urinary System and Male Genital Organs", neuroendocrine tumours are classified into four subtypes: small cell neuroendocrine carcinoma (SCNC), large cell neuroendocrine carcinoma (LCNC), well-differentiated neuroendocrine tumour (carcinoid tumour) and paraganglioma. LCNC is exceedingly rare in the bladder (2). Although the types of neuroendocrine tumours of the bladder are not as common as neuroendocrine neoplasms of the lungs, the differential diagnosis of these tumours is still crucial and should be considered in uropathology. The knowledge of this diagnosis is critical to advance the uropathological field and accelerate drug development with inclusion, rather than exclusion, of patients with SCNC and other variants of neuroendocrine tumours of the bladder. Therefore, in this review, the bladder's clinical and uropathological aspects of neuroendocrine tumours are reviewed.

Correspondence: Büşra Yaprak Bayrak MD, Kocaeli University Faculty of Medicine, Department of Pathology, Kocaeli, Turkiye Phone: +90262 3038455 E-mail: busra.yaprakbayrak@kocaeli.edu.tr ORCID-ID: orcid.org/0000-0002-0537-3127 Received: 18.07 .2020 Accepted: 17.09 .2020

Cite this article as: Büşra Yaprak Bayrak. The Clinical and Uropathological Aspects of Neuroendocrine Tumours of the Bladder: A Review. J Urol Surg 2021;8(1):1-7.

๑Copyright 2020 by the Association of Urological Surgery / Journal of Urological Surgery published by Galenos Publishing House. 


\section{A. SCNC}

$\mathrm{SCNC}$, more commonly known as small cell carcinoma, is the most common malignant neuroendocrine neoplasia of the urothelium. It constitutes $0.5 \%-0.7 \%$ of all bladder carcinomas (3). Derived from the urothelium, SCNC has histologically similar features to those seen in the lung (4). However, it is a highgrade invasive disease. The overall 5-year survival rate is low, with reports ranging from 25\% to as low as $8 \%(2,5-7)$. Patients are usually in the seventh or eighth decade of life. It is three times more common in men than in women (8).

\section{Aetiology and Pathogenesis}

SCNC has no known specific aetiology. Studies have shown that the neuroendocrine cells scattered in the normal bladder or metaplasia of the urothelium are derived from malignant transformation or multipotential urothelial stem cells $(2,9,10)$.

Now, SCNC is believed to have a urothelial origin, determined by current molecular data. It has been demonstrated that it is frequently associated with other histological types of conventional urothelial carcinoma of the bladder. Since one of the same risk factors involved in urothelial carcinoma, mainly smoking, is also seen in SCNC, they are proposed to share the same origin $(11,12)$.

Recently, routine standard-of-care DNA sequencing confirms and identifies SCNC as a distinct entity with a predictable mutation profile, similar to SCLC. RNA expression profiling differentiates pure SCNC from urothelial carcinoma (13). At the molecular level, bladder SCNC displays some chromosomal variations, such as inactivation of the tumour suppressor's p53 (encoded by the TP53 gene) and retinoblastoma protein, pRb (encoded by the $R B 1$ gene), similar to that defined in lung SCNC $(11,12)$. Besides this similarity, all SCNC of the bladder harbour promoter mutations of telomerase reverse transcriptase (TERT), which is frequently upregulated in many human cancers, but not identified in SCLC. Multiple studies have demonstrated that up to $70-80 \%$ of urothelial cancers carry the TERT promoter mutations regardless of grade, stage or location $(14,15)$. Publications suggest that these promoters may be clinically measurable potential markers for the differential diagnosis of $\operatorname{SCNC}(11,14,16-18)$.

\section{Clinical Characteristics}

Macroscopic haematuria, dysuria and obstructive symptoms are the most common symptoms of SCNC. Metastases are frequently observed in the regional lymph nodes, and the bones, liver and lung $(2,5,7)$. Brain metastases of SCNC are less common than those of the lung (6).

SCNC of the bladder generally arises in the lateral walls, the dome of the bladder (19-21).

\section{Macroscopic and Microscopic Characteristics}

SCNC usually appears as a single and sizeable polypoid mass. However, it can also be sessile, ulcerated and occasionally infiltrative. Most are invasive at least to the level of the muscularis propria. Histologically, SCNC tumours are arranged as sheets or islands of small to medium-sized cells with narrow cytoplasm, separated by the limited stroma. These cells have small, round to oval, overlapping nuclei with finely distributed chromatin, without prominent nucleoli (2) (Figure 1).

The Azzopardi effect, a histomorphologic phenomenon of incrustation of the blood vessel wall with basophilic nuclear material, indicates the tumour's high proliferative activity. Vascular invasion, mitosis and coagulative necrosis are common in $\operatorname{SCNC}(2,3)$.

For a tumour to be classified as SCNC histopathologically, small cell histology must be found in most of the tumour. Approximately $40-50 \%$ of cases have non-small cell carcinomas, such as carcinoma in situ, classical urothelial carcinoma, squamous cell carcinoma, adenocarcinoma and sarcomatoid carcinoma. The appearance of these morphologies does not exclude the diagnosis of $\operatorname{SCNC}(2,5,9,22)$.

Tumour cells immunohistochemically show both epithelial and neuroendocrine differentiation. Tumour cells are stained with synaptophysin, chromogranin and cytokeratin. Extensive staining is seen with Ki-67. Thyroid transcription factor-1 (TFF1) staining occurs in half of the cases $(23,24)$.

Metastases from other organs should be excluded to accept $\mathrm{SCNC}$ as a primary urinary bladder tumour. Differential diagnosis

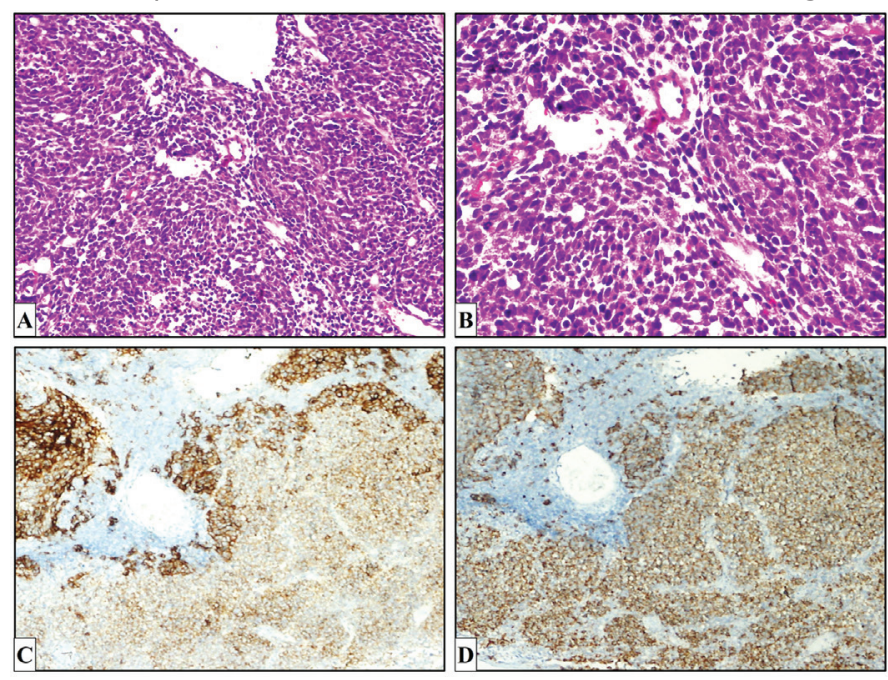

Figure 1. Small cells with ill-defined borders, scant cytoplasm, finely granular nuclear chromatin and absent nucleoli, $\mathrm{HCE}_{1}(\mathrm{~A}) \times 100$; malignant epithelial tumour- consisting with prominent nuclear moulding- are round and ovalshaped, HEE, (B) x200; micrographs of CD56 immunostainings, original magnification: (C) $\times 100$; micrographs of synaptophysin immunostainings, original magnification: (D) $\times 100$ 
should include lymphoma, lymphoepithelioma-like carcinoma, plasmacytoid carcinoma and poorly differentiated urothelial carcinoma. In these cases, immunostaining with TTF-1, GATA-3 and p63 would support the diagnosis of SCNC.

\section{Treatment}

Since SCNC is rare, the surgical or medical standard treatment strategies are not well established. Systemic chemotherapy, surgery and radiotherapy are the available treatment modalities. Some clinics perform radical cystectomy in non-metastatic cases. The chemotherapy applied is the same as that used in lung SCNC. In many clinics, adjuvant chemotherapy and radiotherapy or neoadjuvant chemotherapy and partial/radical cystectomy combinations are recommended. Due to its poor prognosis regardless of the treatment applied and low overall survival, research should be continued for new therapeutic agents specific for bladder SCNC (8).

\section{B. LCNC}

As a high-grade neuroendocrine tumour, the incidence of LCNC of the bladder is rare, with only a few case reports in the literature. Most cases have reported an aggressive clinical course, often with metastasis $(25,26)$. The prognosis resembles that of SCNC.

\section{Aetiology and Pathogenesis}

The etiological factors for LCNC includes the personal or family history of cancer, possibly because of genetic predisposition, iatrogenic causes (chemotherapy- or radiotherapy-related factors e.g., postprostate-cancer external beam radiation therapy), or common environmental exposure (e.g., smoking) $(27,28)$. As in SCNC pathogenesis, the most common hypothesis for LCNC include the origin of the multipotent urothelial stem cells that can differentiate into various cell types $(29,30)$.

\section{Clinical Characteristics}

The clinical presentation of LCNC resembles conventional urothelial bladder carcinoma, with gross haematuria, which is a frequently observed symptom, and less frequently, dysuria and mucosuria, or no symptoms at presentation $(29,31)$. Distant metastases have been reported mostly to the liver and lung (32$34)$. Both brain and skin metastases of the bladder LCNC have also been reported $(29,33,35)$.

\section{Macroscopic and Microscopic Characteristics}

Macroscopically, LCNC presents in $4 \mathrm{~cm}$ diameter lesions, including nodular/polypoid, single, solid tumours, mostly located in the lateral bladder wall $(2,8,29,36,37)$.

The tumour is a high-grade and poorly differentiated neoplasm exhibiting neuroendocrine features on HEtE staining, high mitotic activity and necrosis, and immunohistochemical evidence of neuroendocrine differentiation.
Neoplastic cells are organised in sheet-like, trabecular palisading, or organoid nested growth patterns. Single cells are large, polygonal, with abundant cytoplasm and low nuclear to cytoplasmic ratio. Their nuclei are often large, polymorphic, oval, featuring coarse, granular or vesicular chromatin, often with prominent nucleoli (Figure 2). Occasional giant cells may be observed (38). Compared with SCNC, rosettes are often observed $(2,26,29,39-41)$.

Some reported cases were associated with a component of conventional urothelial carcinoma. LCNCs may exist as either pure tumours or mixed forms with varying amounts of conventional urothelial and/or variant histology carcinomatous components (29).

\section{Treatment}

Although surgery alone is not recommended in LCNC cases, it plays an essential role in the accurate management of these cases. For radiotherapy, a bladder-sparing protocol seems to be less effective than radical surgery, but data remain contradictory (42). Since LCNC has potentially aggressive behaviour, early diagnosis and treatment with radical cystectomy and neoadjuvant or adjuvant chemotherapy may offer long-term control of a localised tumour. They may extend the overall survival of patients (34).

\section{Well-differentiated Neuroendocrine Tumour (Carcinoid Tumour)}

Well-differentiated neuroendocrine tumour, formerly named as carcinoid tumour, is a neuroendocrine neoplasm resulting from

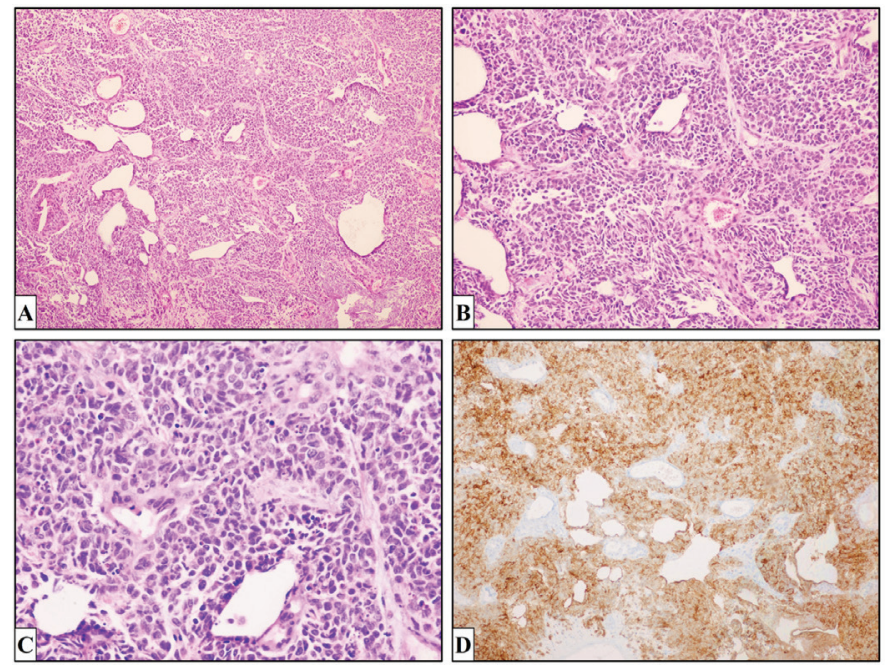

Figure 2. Histopathological section showing tumour tissue located inside the bladder, with neoplastic cells which are arranged in sheet-like, palisading, trabecular growth patterns, $\mathrm{HEE},(\mathrm{A}) \times 40$; malignant cells with abundant cytoplasm are polygonal, large, and low nuclear to cytoplasmic ratio, $\mathrm{HEE}$, (B) $x 100$; nuclei with prominent nucleoli are polymorphic, oval, featuring coarse, vesicular chromatin, $\mathrm{HEE}_{1}$ (C) $\mathrm{x} 200$; micrographs of chromogranin immunostainings, original magnification: (D) x100 
isolated neuroendocrine cells located in the basal layer of the urothelium. These cells may become more abundant in reactive conditions. Well-differentiated neuroendocrine tumours have been rarely described in the true primary bladder $(2,43)$. The patients were in the same age range associated with usual urothelial carcinoma.

The distinctive small well-differentiated neuroendocrine tumour is associated with a good prognosis. However, well-differentiated neuroendocrine tumours of the bladder may rarely present as muscle-invasive tumours, which must be distinguished from metastasis from other sites, such as the gastrointestinal tract (44).

\section{Aetiology and Pathogenesis}

Derived from the urothelium, well-differentiated neuroendocrine tumours are potentially malignant neuroendocrine tumours (45). These tumours' pathogenesis is believed to resemble SCNC of the bladder closely.

\section{Clinical Characteristics}

Haematuria is the most classical clinical presentation of welldifferentiated neuroendocrine tumours, followed by irritative voiding symptoms. These tumours are generally observed in the bladder neck and trigone. Their relationship with Carcinoid syndrome has not been reported (2).

\section{Macroscopic and Microscopic Characteristics}

Well-differentiated neuroendocrine tumours characteristically present as small (mean diameter of $5 \mathrm{~mm}$ ) polypoid masses restricted to the lamina propria. Histopathologically, these tumours exhibit the same typical features described at other sites, including uniform cells with round nuclei containing stippled chromatin, often with intracytoplasmic eosinophilic granules resembling Paneth cells. Hence, these lesions occasionally resemble adenocarcinoma. A distinctive feature of small well-differentiated neuroendocrine tumours is that the cells are arranged in a pseudoglandular pattern associated with cystitis cystica and cystitis glandularis, resulting in their misdiagnosis as a non-neoplastic condition. In rare cases, anastomosing trabeculae, nests and cords of cells without the prominent pseudoglandular morphology have been demonstrated in smaller superficial lesions. These welldifferentiated neuroendocrine tumours are aggressive, express neuroendocrine markers immunohistochemically, and express prostate-specific acid phosphatase, but do not express other prostate markers $(2,45)$.

\section{Treatment}

At present, there are no standard treatment guidelines for the management of well-differentiated neuroendocrine tumours.
Metaiodobenzylguanidine therapy may offer some benefit in the adjuvant settings in specific cases, especially those considered not suitable for chemotherapy $(2,45)$.

\section{Paraganglioma}

The primary paraganglioma is very rare among neuroendocrine tumours of the bladder, accounting for $0.05 \%$ of all bladder tumours. In contrast to SCNC and LCNC, paraganglioma is more common among females and whites $(2,46)$.

\section{Aetiology and Pathogenesis}

Paraganglioma of the bladder derives from the paraganglion cells in the bladder wall. Although the exact aetiology is unknown, paraganglioma develops from the chromaffin tissue of the sympathetic nervous system (47).

\section{Clinical Characteristics}

Paraganglioma can locate in any part of the bladder and at any level of the bladder wall, preferring the detrusor muscle more. The most common sites of paraganglioma are the dome and trigone of the bladder (2). Paraganglioma patients may present with hypertension and hypertensive crisis during micturition and with headache, palpitation, blurred vision, and intermittent gross haematuria, based on the functional (i.e., secrete catecholamine) or non-functional features (48).

\section{Macroscopic and Microscopic Characteristics}

Cystoscopically, paragangliomas are well-circumscribed, dome-shaped/exophytic nodules smaller than $3.9-\mathrm{cm}$ in size, covered with an intact mucosa but ulcerations can also exist. Unlike the extraadrenal ones found in other localisations, they exhibit malignant behaviour in a ratio of $20 \%$. There is no definitive histopathological finding showing the distinction between malignant and benign disease. The presence of nuclear pleomorphism, mitosis and necrosis are unreliable findings in determining its clinical behaviour. The definitive malignancy criterion for these tumours is the presence of regional or distant metastases $(2,49)$.

Histopathologically, paraganglioma consists of eosinophilic or granular cytoplasm and polygonal epithelioid or round cells. Nuclei are localised centrally, including vesicular and finely granular chromatin. Cells are present in an organoid/nest pattern called a Zellballen. These nests comprise the surrounding blood sinus and fibrous stroma (Figure 3). Immunohistochemically, cells are stained positive with chromogranin, synaptophysin and neuron-specific enolase. Sustentacular cells are stained with S100 $(46,47)$.

\section{Treatment}

Complete resection is the most pivotal treatment of paraganglioma. However, there are other available strategies 

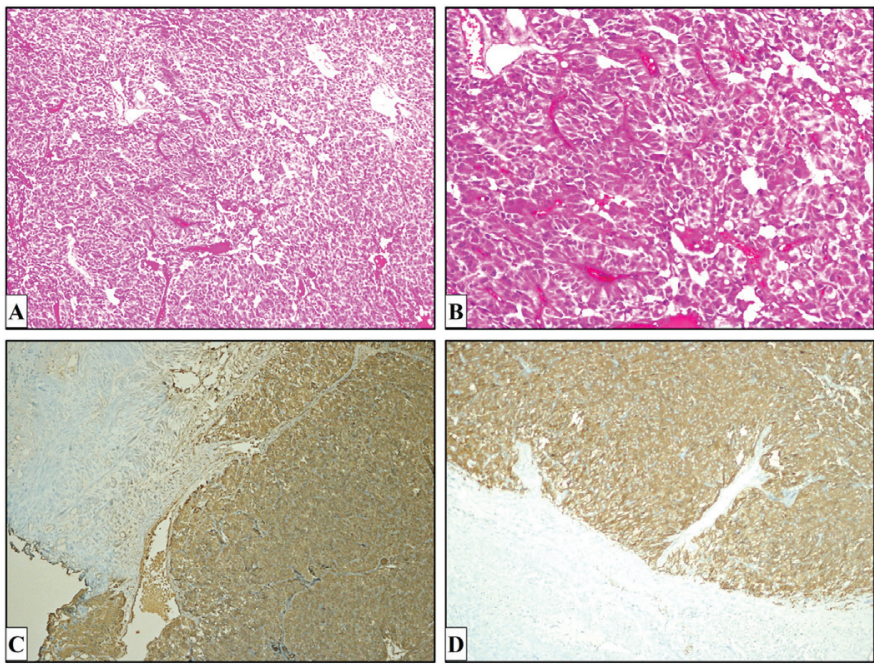

Figure 3. The trabecular pattern of neoplastic cells within a prominent vascular network, HEE, (A) x100; round cells with abundant eosinophilic finely granular cytoplasm, HEE, (B) x200; micrographs of chromogranin immunostainings, original magnification: (C) $\times 100$; micrographs of CD56 immunostainings, original magnification: (D) $\times 100$

depending on the disease stage, such as endourethral surgeries, including electrocision and laser resection, partial or radical cystectomy. Recently, minimally invasive surgery is increasingly replacing open surgery, which was generally performed in the past (47).

\section{Conclusion}

Neuroendocrine bladder tumours are rare variants, such as small cell or LCNC, well-differentiated neuroendocrine tumours, and paraganglioma varieties, based on 2016 WHO Classification of Tumours of the Urinary System and Male Genital Organ classification system. This classification provides a useful platform to discuss the aetiology, pathogenesis, clinical and pathological characteristics of neuroendocrine tumours of the urinary bladder. The overall prognosis for urinary bladder neuroendocrine carcinomas is worse than the prognosis of urothelial carcinoma. In some cases, a small cell neuroendocrinelike subtype has been defined, having high expression of the neuronal marker and poor outcomes (50). Particularly, most neuroendocrine-like tumours did not have histological features consistent with neuroendocrine bladder tumours but were phenotypically similar to conventional urothelial carcinoma. Early and accurate differential diagnosis of neuroendocrine-like tumours may be possible by genomic analysis, which improves patient outcomes for the management of treatment, regardless of histological presentation (51).

Developing technologies in the genetic and cellular investigations, various advances are expected in the clinical characterisation, prognosis, and treatment of neuroendocrine tumours of the bladder. Based on the information reviewed on urology practice, diagnosis, treatment or follow-up, there is currently no recommended scientific guideline to use routinely. In summary, TUR-biopsy is the gold standard method in the differential diagnosis of neuroendocrine bladder tumours and immunohistochemical investigations.

\section{Acknowledgements}

All authors contributed to concepts, design, definition of intellectual content, literature search, clinical studies, data acquisition, data analysis, manuscript preparation, manuscript editing, and manuscript review. All author took responsibility of the integrity of the work as a whole from inception to published article and were designated as "guarantor". Special thanks to Prof. Dr. Kutsal Yörükoğlu for microscopic photographs.

Peer-review: Externally and internally peer-reviewed.

Conflict of Interest: No conflict of interest was declared by the authors.

Financial Disclosure: The authors declared that this study received no financial support.

\section{References}

1. Sehgal SS, Wein AJ, Bing Z, Malkowicz SB, Guzzo TJ. Neuroendocrine tumor of the bladder. Rev Urol 2010;12:e197-e201.

2. Humphrey PA, Moch H, Cubilla AL, Ulbright TM, Reuter VE. The 2016 WHO Classification of Tumours of the Urinary System and Male Genital OrgansPart B: Prostate and Bladder Tumours. Eur Urol 2016;70:106-119.

3. Kaffash Nayeri R, Sadri M, Shahrokh H, Abolhasani M, Khaleghimehr F, Zolfi E, Yousefzadeh Kandevani N, Kashi AH. Small Cell Carcinoma of Bladder; Still A Diagnostic and Therapeutic Challenge: Seven Years of Experience and Follow-up in A Referral Center. Urol J 2020;17:363-369.

4. Chang MT, Penson A, Desai NB, Socci ND, Shen R, Seshan VE, Kundra $R$, Abeshouse A, Viale A, Cha EK, Hao X, Reuter VE, Rudin CM, Bochner $\mathrm{BH}$, Rosenberg JE, Bajorin DF, Schultz N, Berger MF, lyer G, Solit DB, AlAhmadie HA, Taylor BS. Small-Cell Carcinomas of the Bladder and Lung Are Characterized by a Convergent but Distinct Pathogenesis. Clin Cancer Res 2018;24:1965-1973.

5. Choong NW, Quevedo JF, Kaur JS. Small cell carcinoma of the urinary bladder The Mayo Clinic experience. Cancer 2005;103:1172-1178.

6. Mukesh $\mathrm{M}$, Cook N, Hollingdale AE, Ainsworth NL, Russell SG. Small cell carcinoma of the urinary bladder: a 15 -year retrospective review of treatment and survival in the Anglian Cancer Network. BJU Int 2009;103:747-752.

7. Trias I, Algaba $F$, Condom E, Español I, Segui J, Orsola I, Villavicencio $H$, Garcia Del Muro X. Small cell carcinoma of the urinary bladder. Presentation of 23 cases and review of 134 published cases. Eur Urol 2001;39:85-90.

8. Niu Q, Lu Y, Xu S, Shi Q, Guo B, Guo Z, Huang T, Wu Y, Yu J. Clinicopathological characteristics and survival outcomes of bladder neuroendocrine carcinomas: a population-based study. Cancer Manag Res 2018;10:44794489.

9. Abbas F, Civantos F, Benedetto P, Soloway MS. Small cell carcinoma of the bladder and prostate. Urology 1995;46:617-630. Review.

10. Blomjous CE, Vos W, De Voogt HJ, Van der Valk P, Meijer CJ. Small cell carcinoma of the urinary bladder. A clinicopathologic, morphometric, 
immunohistochemical, and ultrastructural study of 18 cases. Cancer 1989;64:1347-1357.

11. Wang $Y$, Li $Q$, Wang J, Tong $M$, Xing H, Xue $Y$, Pan H, Huang C, Li D. Small cell carcinoma of the bladder: the characteristics of molecular alterations, treatment, and follow-up. Med Oncol 2019;36:98.

12. Meder L, Konig K, Ozretic L, Schultheis AM, Ueckeroth $F$, Ade $C P$, et al. NOTCH, ASCL1, p53 and RB alterations defne an alternative pathway driving neuroendocrine and small cell lung carcinomas. Int J Cancer 2016;138:927-938.

13. Hoffman-Censits J, Choi W, Pal S, Trabulsi E, Kelly WK, Hahn NM, McConkey D, Comperat E, Matoso A, Cussenot O, Cancel-Tassin G, Fong MHY, Ross J, Madison R, Ali S. Urothelial Cancers with Small Cell Variant Histology Have Confirmed High Tumor Mutational Burden, Frequent TP53 and RB Mutations, and a Unique Gene Expression Profile. Eur Urol Oncol 2020;S2588-9311(19)30168-30163.

14. Zheng $X$, Zhuge J, Bezerra SM, Faraj SF, Munari E, Fallon JT 3rd, Yang XJ, Argani $P$, Netto GJ, Zhong M. High frequency of TERT promoter mutation in small cell carcinoma of bladder, but not in small cell carcinoma of other origins. J Hematol Oncol 2014;7:47.

15. Kinde I, Munari E, Faraj SF, Hruban RH, Schoenberg M, Bivalacqua T, Allaf M, Springer S, Wang Y, Diaz LA Jr, Kinzler KW, Vogelstein B, Papadopoulos N, Netto GJ: TERT promoter mutations occur early in urothelial neoplasia and are biomarkers of early disease and disease recurrence in urine. Cancer Res 2013;73:7162-7167.

16. Shen $P$, Jing $Y$, Zhang $R$, Cai MC, Ma $P$, Chen $H$, Zhuang G. Comprehensive genomic profiling of neuroendocrine bladder cancer pinpoints molecular origin and potential therapeutics. Oncogene 2018;37:3039-3044.

17. Rickman DS, Beltran $H$, Demichelis F, Rubin MA. Biology and evolution of poorly diferentiated neuroendocrine tumors. Nat Med 2017;23:1-10.

18. Avogbe PH, Manel A, Vian E, Durand G, Forey N, Forey N, Voegele C, Zvereva M, Hosen MI, Meziani S, De Tilly B, Polo G, Lole O, Francois P, Delhomme TM, Carreira C, Monteiro-Reis S, Henrique R, Abedi-Ardekani B, Byrnes G, Foll M, Weiderpass E, McKay J, Jeronimo C, Scelo G, Le Calvez-Kelm F. Urinary TERT promoter mutations as non-invasive biomarkers for the comprehensive detection of urothelial cancer. EBioMedicine 2019;44:431-438.

19. Tamas EF, Stephenson AJ, Campbell SC, Montague DK, Trusty DC, Hansel DE. Histopathologic features and clinical outcomes in 71 cases of bladder diverticula. Arch Pathol Lab Med 2009;133:791-796.

20. Tudor J, Cantley RL, Jain S. Primary small cell carcinoma arising from a bladder diverticulum. J Urol 2014;192:236-237.

21. Zhong H, George S, Kauffman E, Guru K, Azabdaftari G, Xu B. Clinicopathologic characterization of intradiverticular carcinoma of urinary bladder - a study of 22 cases from a single cancer center. Diagn Pathol 2014;9:222.

22. Ali SZ, Reuter VE, Zakowski MF. Small cell neuroendocrine carcinoma of the urinary bladder. A clinicopathologic study with emphasis on cytologic features. Cancer 1997;79:356-361.

23. Agoff SN, Lamps LW, Philip AT, Amin MB, Schmidt RA, True LD, Folpe AL. Thyroid transcription factor- 1 is expressed in extrapulmonary small cell carcinomas but not in other extrapulmonary neuroendocrine tumors. Mod Pathol 2000;13:238-242.

24. Jones TD, Kernek KM, Yang XJ, Lopez-Beltran A, MacLennan GT, Eble JN,

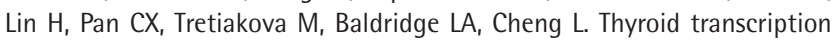
factor 1 expression in small cell carcinoma of the urinary bladder: an immunohistochemical profile of 44 cases. Hum Pathol 2005;36:718-723.

25. Colarossi C, Pino P, Giuffrida D, Aiello E, Costanzo R, Martinetti D, Memeo L. Large cell neuroendocrine carcinoma (LCNEC) of the urinary bladder: a case report. Diagn Pathol 2013;8:19.

26. Pusiol T, Morichetti D, Zorzi MG. "Pure" primary large cell neuroendocrine carcinoma of the urinary bladder: case report, literature review and diagnostic criteria. Pathologica 2014;106:82-85. Review.
27. Bhatt VR, Loberiza FR Jr, Tandra P, Krishnamurthy J, Shrestha R, Wang J. Risk factors, therapy and survival outcomes of small cell and large cell neuroendocrine carcinoma of urinary bladder. Rare Tumors 2014;6:5043.

28. Zakaria A, Al Share B, Kollepara S, Vakhariya C. External Beam Radiation and Brachytherapy for Prostate Cancer: Is It a Possible Trigger of Large Cell Neuroendocrine Carcinoma of the Urinary Bladder? Case Rep Oncol Med 2017;2017:1853985

29. Sanguedolce F, Calò B, Chirico M, Tortorella S, Carrieri G, Cormio L. Urinary Tract Large Cell Neuroendocrine Carcinoma: Diagnostic, Prognostic and Therapeutic Issues. Anticancer Res 2020;40:2439-2447.

30. Kouba E, Cheng L. Neuroendocrine Tumors of the Urinary Bladder According to the 2016 World Health Organization Classification: Molecular and Clinical Characteristics. Endocr Pathol 2016;27:188-199.

31. Oderda $M$, Ruoppolo $M$, Marson $F$, Pisano F, Fragapane G, Molinaro L, Pacchioni D, Tizzani A, Gontero P. Pathological features and adverse prognosis of a contemporary series of neuroendocrine bladder tumours. Urol Int 2011;86:185-190.

32. Bertaccini A, Marchiori D, Cricca A, Garofalo M, Giovannini C, Manferrari F, Gerace TG, Pernetti R, Martorana G. Neuroendocrine carcinoma of the urinary bladder: case report and review of the literature. Anticancer Res 2008;28:1369-1372.

33. Lee KH, Ryu SB, Lee MC, Park CS, Juhng SW, Choi C. Primary large cell neuroendocrine carcinoma of the urinary bladder. Pathol Int 2006;56:688693.

34. Akamatsu S, Kanamaru S, Ishihara M, Sano T, Soeda A, Hashimoto K. Primary large cell neuroendocrine carcinoma of the urinary bladder. Int $J$ Urol 2008;15:1080-1083.

35. Tsugu $A$, Yoshiyama $M$, Matsumae $M$. Brain metastasis from large cell neuroendocrine carcinoma of the urinary bladder. Surg Neurol Int 2011;2:84.

36. Martin IJ, Vilar DG, Aguado JM, Perelló CG, Aliaga MR, Argente VG, Ferreres LA, Gómez JG. Large cell neuroendocrine carcinoma of the urinary bladder. Bibliographic review. Arch Esp Urol 2011;64:105-113.

37. Zhou HH, Liu LY, Yu GH, Qu GM, Gong PY, Yu X, Yang P. Analysis of clinicopathological features and prognostic factors in 39 cases of bladder neuroendocrine carcinoma. Anticancer Res 2017;37:4529-4537.

38. Park $\mathrm{S}$, Reuter VE, Hansel DE. Non-urothelial carcinomas of the bladder. Histopathology 2019;74:97-111.

39. Radović N, Turner R, Bacalja J. Primary "Pure" large cell neuroendocrine carcinoma of the urinary bladder: a case report and review of the literature. Clin Genitourin Cancer 2015;13:e375-e377.

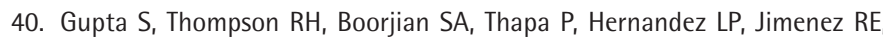
Costello BA, Frank I, Cheville JC. High grade neuroendocrine carcinoma of the urinary bladder treated by radical cystectomy: a series of small cell, mixed neuroendocrine and large cell neuroendocrine carcinoma. Pathology 2015; $47: 533-542$

41. Sari A, Ermete $M$, Sadullahoğlu C, Bal $K$, Bolükbaşi A. Large cell neuroendocrine carcinoma of urinary bladder; case presentation. Turk Patoloji Derg 2013;29:138-142.

42. Evans AJ, Al-Maghrabi J, Tsihlias J, Lajoie G, Sweet JM, Chapman WB. Primary large cell neuroendocrine carcinoma of the urinary bladder. Arch Pathol Lab Med 2002;126:1229-1232.

43. Chen YB, Epstein JI. Primary carcinoid tumors of the urinary bladder and prostatic urethra: a clinicopathologic study of 6 cases. Am J Surg Pathol 2011;35:442-446.

44. Baydar DE, Tasar C. Carcinoid tumor in the urinary bladder: unreported features. Am J Surg Pathol 2011;35:1754-1757.

45. Dadhwal R, Jain S, Seth A, Bal CS. Neuroendocrine tumour of urinary bladder: a rare case of aggressively behaving primary well-differentiated 
neuroendocrine tumour with review of literature. BMJ Case Rep 2019;12:e231061.

46. Beilan JA, Lawton A, Hajdenberg J, Rosser CJ. Pheochromocytoma of the urinary bladder: a systematic review of the contemporary literature. BMC Urol 2013;13:22.

47. Zhai H, Ma X, Nie W, Li H, Peng C, Li X, Zhang Y, Zhang X. Paraganglioma of the Urinary Bladder: A Series of 22 Cases in a Single Center. Clin Genitourin Cancer 2017;15:e765-e771.

48. Nakajo $M$, Nakajo $M$, Fukukura $Y$, Jinguji $M$, Shindo $T$, Nakabeppu $Y$, Kamimura K, Yoneyama T, Takumi K, Yoshiura T. Diagnostic performances of FDG-PET/CT and diffusion-weighted imaging indices for differentiating benign pheochromocytoma from other benign adrenal tumors. Abdom Imaging 2015;40:1655-1665.

49. So JS, Epstein JI. GATA3 expression in paragangliomas: a pitfall potentially leading to misdiagnosis of urothelial carcinoma. Mod Pathol 2013;26:13651370.
50. Robertson AG, Kim J, Al-Ahmadie H, Bellmunt J, Guo G, Cherniack AD, Hinoue T, Laird PW, Hoadley KA, Akbani R, Castro MAA, Gibb EA, Kanchi RS, Gordenin DA, Shukla SA, Sanchez-Vega F, Hansel DE, Czerniak BA, Reuter VE, Su X, de Sa Carvalho B, Chagas VS, Mungall KL, Sadeghi S, Pedamallu CS, Lu Y, Klimczak U, Zhang J, Choo C, Ojesina Al, Bullman S, Leraas KM, Lichtenberg TM, Wu CJ, Schultz N, Getz G, Meyerson M, Mills GB, McConkey DJ; TCGA Research Network, Weinstein JN, Kwiatkowski DJ, Lerner SP. Comprehensive Molecular Characterization of Muscle-Invasive Bladder Cancer. Cell 2017;171:540-556.e25.

51. Batista da Costa J, Gibb EA, Bivalacqua TJ, Liu Y, Oo HZ, Miyamoto DT, Alshalalfa M, Davicioni E, Wright J, Dall'Era MA, Douglas J, Boormans JL, Van der Heijden MS, Wu CL, van Rhijn BWG, Gupta S, Grivas P, Mouw KW, Murugan P, Fazli L, Ra S, Konety BR, Seiler R, Daneshmand S, Mian OY, Efstathiou JA, Lotan Y, Black PC. Molecular Characterization of Neuroendocrine-like Bladder Cancer. Clin Cancer Res 2019;25:3908-3920. 